Seminar Nasional Teknologi Informasi dan Kedirgantaraan (SENATIK)

Vol. III, 21 Desember 2017, P-ISSN: 2337-3881, E-ISSN: 2528-1666

DOI: http://dx.doi.org/10.28989/senatik.v3i0.109

\title{
PENDEKATAN LEAN SIX SIGMA DAN TAGUCHI UNTUK MENGATASI MASALAH PENGEMASAN DAN PEMASARAN PRODUK WEDANG UWUH INSTAN SRUPUT
}

\author{
Elly Wuryaningtyas Yunitasari ${ }^{1}$, Emmy Nurhayati ${ }^{2}$ \\ Program Studi Teknik Industri, Fakultas Teknik \\ Universitas Sarjanawiyata Tamansiswa \\ Jl. Kusumanegara No. 157 Yogyakarta 55165 \\ Email : ${ }^{1}$ ellywy@ustjogja.ac.id, ${ }^{2}$ emmynurhayati@gmail.com
}

\begin{abstract}
Wedang Uwuh Instan Sruput is one of the business unit of Industrial Engineering Program,Faculty of Engineering, Universitas Sarjanawiyata Tamansiswa Yogyakarta.Wedang Uwuh Sruput is an innovative manufacture of wedang uwuh into instant from the original form of whole and raw spices. The resulting product results sometimes have different quality/taste in each production process. The purpose of this research is to improve product quality of Wedang Uwuh Instan Sruput,improve the composition of herb wedang uwuh product,improve the concept of packaging and improve the marketing of the wedang uwuh products. The object of this research is Wedang Uwuh Sruput Prodi Teknik Industri UST.The materials used are instant wedang uwuh maker such as ginger,clove leafcinnamon leaf secang wood, cloves, lemongrass, sugar and water.Identification is done on factors that affect product quality in order to create the same product in the market.The experiment was conducted by performing several times of Wedang Uwuh Sruput production with several variations of composition/formula using Taguchi method to maintain product consistency and quality. In this experiment there are 4 factors(sugar, ginger,water and secang)with 3 level design,that is 2,8 $\mathrm{kg} ; 2.9 \mathrm{~kg}$ and $3.0 \mathrm{~kg}$ for sugar, $1.0 \mathrm{~kg} ; 1.2 \mathrm{~kg}$ and $1.4 \mathrm{~kg}$ for ginger,water is $5.0 \mathrm{~L} ; 5.2 \mathrm{~L}$ and 5.4 $L$, while the secang is $200 \mathrm{gr}, 210 \mathrm{gr}, 220 \mathrm{gr}$.The difference of the output of Wedang Uwuh Sruput is caused by the difference of sugar content, the difference of ginger content, the difference of the amount of water and the difference of the number of secang used,the use of different raw material specification, the length of production process is not same and the production process is still manual.The result shows that Waste which has the highest weight is waiting with the value of 0.252 at rank 31.Then the calculation of sigma value at early check is at the level of 3,001 sigma and final check at 2,455 sigma level.From the calculation of sigma level can be seen that the level of quality in Business Unit Wedang Uwuh "Sruput" is still far from lean six sigma target.Therefore, the advice given to the Business Unit Wedang Uwuh "Sruput" in the form of corrective actions that have been analyzed in this study.It was found that the most appropriate composition based on consumer preferences was Sugar $2.9 \mathrm{~kg}$; Ginger 1.4; Water 5 $L$; and Wood Secang $200 \mathrm{gr}$.
\end{abstract}

Keywords: Lean Six Sigma, Taguchi, Packaging, Marketing, Wedang Uwuh Instan Sruput ramuan produk wedang uwuh serta pemasaran dari produk wedang uwuh

\section{PENDAHULUAN}

Produk Wedang Uwuh Instan Sruput adalah minuman tradisional yang diangkat menjadi minuman konsumtif masyarakat zaman sekarang.Pada produk Wedang Uwuh Instan Sruput ini ada beberapa permasalahan yaitu kualitas produk wedang uwuh,komposisi tersebut.Karakter wedang uwuh yang berkualitas terlihat dari

rasa dan warna yang dihasilkan.Melalui pendekatan metode Lean Six Sigma dan Taguchi ini perusahaan dapat melakukan 
eksperimen untuk mendapatkan formula yang tepat melalui tiga tahapan yaitu tahap perencanaan eksperimen,tahap pelaksanaan eksperimen dan tahap analisis.Tujuan penelitian ini adalah memperbaiki kualitas produk Wedang Uwuh Instan Sruput,memperbaiki komposisi ramuan produk wedang uwuh, memperbaiki konsep pengemasan serta memperbaiki pemasaran dari produk wedang uwuh tersebut.

Beberapa penelitian pernah dilakukan diantaranya oleh Vitho Ivan pada tahun 2013.Hasil penelitian menunjukkan faktor dominan penyebab kecacatan adalah faktor kadar PRI.Dari hasil FMEA didapat penyebab kecacatan bahan baku berkualitas rendah adalah karena banyak mengandung kotoran (remah kayu,tanah dan lainnya), proses pencucian kurang bersih karena menggunakan air yang kotor serta proses penjemuran dan pengeringan kurang baik dengan waktu yang relatif cepat. Penelitian oleh Moh. Hartono pada tahun 2012,manfaat yang diharapkan bagi industri dengan penelitian ini adalah meningkatkan mutu produk plastik.Penelitian oleh Didik Wahjudi, Yohan Pramono(2011), dilakukan penelitian untuk mendapatkan faktor yang berpengaruh dan mengetahui besar pengaruh dari masing-masing faktor tersebut kemudian mengetahui level yang tepat bagi tiap faktor sehingga proses produksi mencapai tingkat kecacatan minimum. Penelitian oleh Dodi Aneka Putra(2013), dengan melakukan pengendalian kualitas produk kerupuk dengan metode taguchi.

\section{METODE PENELITIAN}

\subsection{Objek dan Lokasi Penelitian}

Objek pada penelitian ini adalah Wedang Uwuh Instan Sruput dengan lokasi penelitian dilakukan di Laboratorium Program Studi Teknik Industri Universitas Sarjanawiyata Tamansiswa Yogyakarta.

2.2 Jenis dan Sumber Data

Data yang digunakan adalah data primer diperoleh dengan melakukan pengamatan dan wawancara langsung kepada pihak-pihak yang berkompeten pada produk Wedang Uwuh Instan Sruput.Data sekunder diperoleh dari laporan tahunan atau bulanan yang meliputi data historis, data kualitas produk dan studi literatur.
2.3 Metode Pengumpulan Data

1. Studi Lapangan

a.Pengamatan Langsung (Observasi)

b.Wawancara (Interview)

c.Dokumentasi Data

1. Proses bisnis produk Wedang UwuhInstan Sruput

2. Diagram Alir Proses Produksi

3. Data Early Check Repaire dan Reject produk

4. Data kriteria kualitas

d. Studi Kepustakaan

2.4 Metode Pengolahan Data

a. Define

Untuk mengidentifikasi waste yang ada dalam proses produksi.Tools yang digunakan:

1. Supplier,input, process, output, customer (SIPOC)

2. Critical to Quality (CTQ)

b. Measure

Pengukuran tingkat kinerja proses pada saat sekarang yang akan dibandingkan dengan target yang telah ditetapkan.Tools yang digunakan:

1. Big Picture Mapping

Memvisualisasikan proses produksi secara menyeluruh untuk mengetahui seluruh jenis pemborosan.

\section{Sigma Level}

Variabel ini mengindikasikan variabilitas proses dan sampai level berapa sigma proses yang dikelola.

c. Analyze

Analyze adalah fase menganalisis faktor-faktor penyebab masalah/cacat.Tools yang digunakan:

1. Pareto Diagram

2. Cause effect Diagram

3. Five Why's Diagram

Tool ini membantu mengidentifikasi akar masalah atau penyebab dari sebuah ketidaksesuaian pada proses atau produk.

d. Improve

Pada tahap improve akan diberikan beberapa rekomendasi perbaikan terkait dengan waste yang terjadi sepanjang value stream pada proses produksi.Tool yang digunakan:

1. Metode $5 \mathrm{~W}+1 \mathrm{H}$

Analisis yang digunakan untuk melakukan penanggulangan terhadap setiap akar 
permasalahan melalui langkah analisa What, Why, When, Where, Who, dan How.

e. Control

Melakukan pengendalian terhadap proses secara terus-menerus dengan membuat perencanaan pengendalian serta menggunakan Standard Operating Procedure (SOP) sebagai alat Control-nya.

\section{HASIL DAN PEMBAHASAN}

\subsection{Data Laporan Seleksi}

Data laporan seleksi pada bagian pengendalian kualitas di Unit Usaha Wedang Uwuh "Sruput" berupa data Earlycheck, Final check dan data produk cacat afkir.

3.2 Pengolahan Data

\section{Define}

Diagram SIPOC

Informasi mengenai elemen-elemen yang terkait dalam proses produksi dapat diamati pada gambar 1 berikut ini:

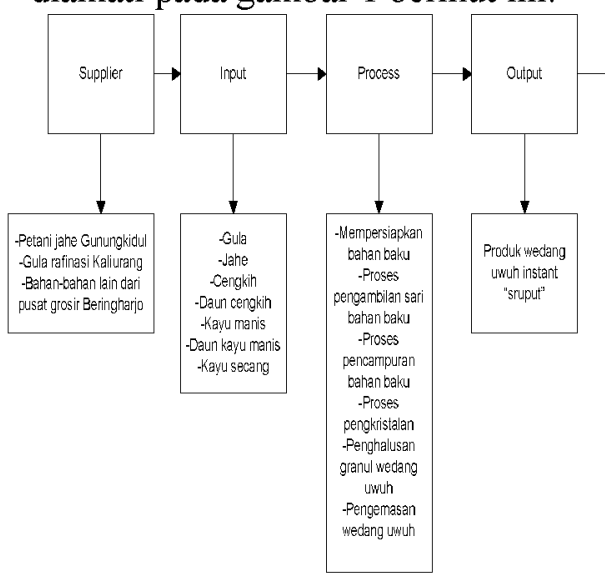

Gambar 1. Diagram SIPOC

\section{Critical to Quality}

Penentuan Critical to Quality dilakukan dengan cara mengidentifikasi kriteria karakteristik kualitas yang menimbulkan potensi untuk menimbulkan kecacatan. Kriteria cacat produk Wedang Uwuh "Sruput" yang masih dapat diperbaiki adalah sebagai berikut:

1. Kemasan plastik kurang rapi

Proses sealer-nya kurang sempurna sehingga kemasan plastiknya tidak rapi sehingga masuk dalam cacat produk.

2. Kemasan box kurang rapi

Melipat bagian box tidak sesuai pola sehingga jika sudah terbentuk box menjadi tidak rapi. Proses melipat yang tidak mengikuti pola dapat menyebabkan kecacatan produk.

Sedangkan kriteria untuk produk cacat yang harus dilakukan penggantian (Afkir) adalah sebagai berikut:

1. Rasa kurang manis

Kualitas ini berhubungan dengan komposisi ramuannya. Penyebab yang bisa terjadi adalah komposisi dan takaran ramuan belum pas.

2. Warna kurang menarik

Kualitas ini berhubungan dengan komposisi ramuannya. Penyebab yang bisa terjadi adalah komposisi dan takaran ramuan belum pas.

3. Butiran kurang halus Kualitas ini berhubungan dengan proses blender dan penyaringan yang kurang sempurna.

Hasil Early Check

Tabel 1 Cacat hasil laporan Early Checkmerupakan hasil pengolahan data dari laporan Early Check:

Tabel 1 Cacat hasil laporan Early Check

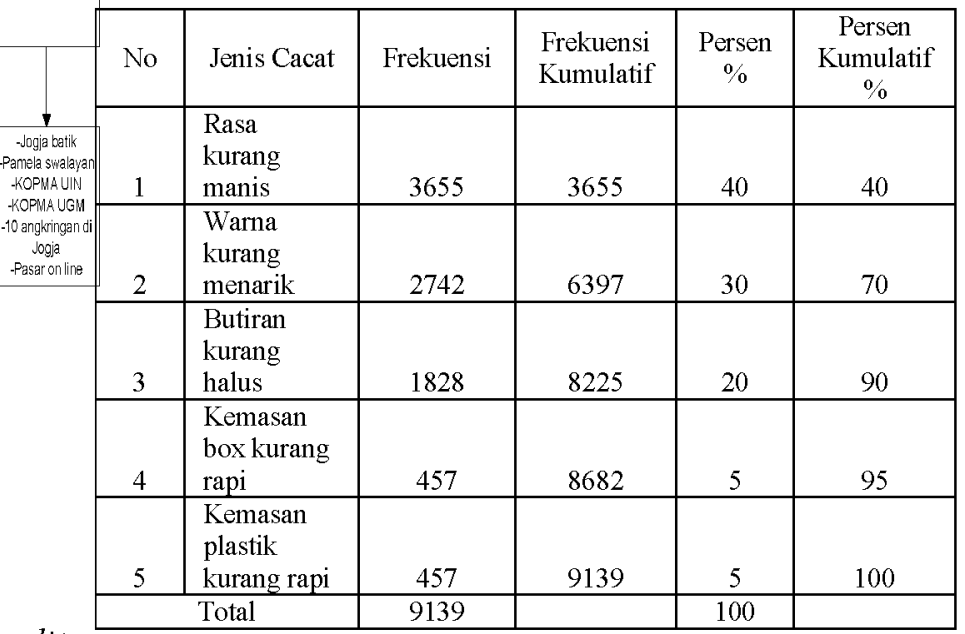

Sumber: Unit Usaha Wedang Uwuh "Sruput"Dari hasil pengolahan data pada Tabel 1 diatas dapat dilihatyang menjadi Critical to Quality dari data tersebut adalah jumlah cacat terbanyak dari jenis cacat yaitu rasa kurang manis sebanyak $40 \%$.

Final Check

Pemeriksaan produk pada tahap Final Check merupakan seleksi akhir yang lebih teliti sehingga seluruh produk dari hasil seleksi dibawa ke bagian Final Check untuk diperiksa kembali.Hasil seleksi dari tahap Final Check akan disajikan dalam 
Tabel 2 Cacat hasil laporan Final Check berikut:Tabel 2 Cacat hasil laporan Final Check

\begin{tabular}{|c|l|c|c|c|c|}
\hline No & Jenis Cacat & $\begin{array}{c}\text { Fekue } \\
\text { nsi }\end{array}$ & $\begin{array}{c}\text { Freku } \\
\text { ensi } \\
\text { Kumu } \\
\text { latif }\end{array}$ & $\begin{array}{c}\text { Pers } \\
\text { en } \\
\%\end{array}$ & $\begin{array}{c}\text { Persen } \\
\text { Kumu } \\
\text { latif\% }\end{array}$ \\
\hline 1 & $\begin{array}{l}\text { Rasa kurang } \\
\text { manis }\end{array}$ & 9138 & 9138 & 40 & 40 \\
\hline 2 & $\begin{array}{l}\text { Warna } \\
\text { kurang } \\
\text { menarik }\end{array}$ & 6854 & 15992 & 30 & 70 \\
\hline 3 & $\begin{array}{l}\text { Butiran } \\
\text { kurang } \\
\text { halus }\end{array}$ & 4569 & 20561 & 20 & 90 \\
\hline 4 & $\begin{array}{l}\text { Kemasan } \\
\text { box kurang } \\
\text { rapi }\end{array}$ & 1142 & 21703 & 5 & 95 \\
\hline & $\begin{array}{l}\text { Kemasan } \\
\text { plastik } \\
\text { kurang rapi }\end{array}$ & 1142 & 22845 & 5 & 100 \\
\hline \multicolumn{7}{|l|}{ Total } & 22845 & & 100 & \\
\hline
\end{tabular}

Sumber: Unit Usaha Wedang Uwuh "Sruput" Dari hasil pengolahan data laporan Final Check diatas dapat dilihatyang menjadi Critical to quality dari data tersebut adalah jumlah cacat terbanyak dari jenis cacat yaitu rasa kurang manis sebanyak $40 \%$.

Penentuan untuk produk yang dinyatakan afkir juga harus diverifikasi oleh bagian Final check agar dapat diproses ulang sehingga tidak terjadi kesalahan hitung pada bagian produksi dan material. Dari hasil pengolahan data jenis cacat produk afkir didapatkan yang menjadi critical to quality dari data tersebut adalah jumlah terbanyak dari jenis cacat yaitu rasa kurang manis sebanyak $44.44 \%$.

Setelah mengetahui hasil Critical to Quality dari masing-masing seleksi maka dapat diambil 3 (tiga) kriteria dari jenis cacat yang menjadi CTQ yaitu rasa kurang manis,warna kurang menarik dan butiran kurang halus.

\section{Measure}

Pengukuran terhadap aktifitas yang berpengaruh dalam pemborosan di Unit Usaha Wedang Uwuh "Sruput" akan dijelaskan pada tahap Measure.Pengukuran akan dilakukan dengan mengidentifikasi Wastemenggunakan menggunakan metode Borda dan perhitungan Sigma Level. Big Picture Mapping
Dalam Big Picture Mapping diuraikan mengenai peta sistem produksi Wedang Uwuh "Sruput" dimulai dari permintaan pelanggan hingga pengiriman yang menghasilkan kepuasan pelanggan. Order produk yang telah diterima akan dilakukan pembuatan sampel produk untuk menghitung kebutuhan bahan baku yang harus disediakan sehingga dapat dibuat perencanaan mengenai jumlah material,kapan material dipesan dan berapa lama pesanan tersebut diselesaikan. Bagian purchasing dan penyimpanan bahan baku memiliki komunikasi dua arah yang saling menginformasikan stock dan jumlah yang harus dibeli. Setelah segala kebutuhan bahan baku tersedia maka akan dibuat schedule untuk bagian produksi.Bagian produksi akan mengatur Schedule dan tugas produksinya mulai dari persiapan bahan baku,pengambilan sari bahan baku,proses pengkristalan,penghalusan granul wedang uwuh hingga produk siap dikemas.

\section{Mengidentifikasi Aliran Proses}

Aliran proses akan diidentifikasi berdasarkan hasil perhitungan tingkat kecacatan dari Critical to Quality.Proses produksi Wedang Uwuh "Sruput" dimulai dari persiapan bahan baku,pengambilan sari bahan baku,proses pengkristalan,penghalusan granul wedang uwuh hingga produk siap dikemas.

Didapatkan dari hasil perhitungan CTQ,ada tiga aktivitas yang sangat berpotensi menimbulkan pemborosan.Adapun pemborosan tersebut terdapat pada aktivitas rasa kurang manis,warna kurang menarik dan butiran kurang halus.

Identifikasi Waste Berpengaruh

Mengidentifikasi waste yang paling berpengaruh dari waste menurut konsep lean dilakukan dengan memberikan kuisioner peringkat pada karyawan yang berkompeten.Pemberian kuisioner ini dilakukan untuk mengetahui tingkat keseringan waste yang terjadi pada proses produksi Wedang Uwuh "Sruput" dengan menggunakan metode Borda yaitu dengan memberikan peringkat untuk masing-masing jenis waste serta mengalikannya dengan bobot yang telah sesuai yaitu peringkat 1 
mempunyai bobot tertinggi yaitu $(\mathrm{n}-1)$ demikian seterusnya. Dimana waste yang mempunyai nilai tertinggi adalah waste yang paling berpengaruh pada proses produksi.

Penyebaran kuisioner diberikan kepada beberapa karyawan yang berpengaruh pada bagian produksi dan bagian kualitas dengan asumsi bahwa karyawan tersebut mengetahui dengan pasti waste yang paling berpangaruh dan waste yang paling sering muncul.Jumlah karyawan yang dipercaya dapat memberikaninformasi yang baik melalui kuisioner ini sebanyak 5 responden.Tabel 3 Urutan Waste Berpengaruh

\begin{tabular}{|l|c|c|}
\hline \multicolumn{1}{|c|}{ Jenis Waste } & Ranking & Bobot \\
\hline Waiting & 31 & 0.252 \\
\hline $\begin{array}{l}\text { Defective } \\
\text { Product }\end{array}$ & 26 & 0.211 \\
\hline Transportation & 24 & 0.195 \\
\hline Inventories & 21 & 0.171 \\
\hline $\begin{array}{l}\text { Over } \\
\text { Production }\end{array}$ & 9 & 0.073 \\
\hline Motion & 4 & 0.033 \\
\hline Over Process & 4 & 0.033 \\
\hline $\begin{array}{l}\text { Under Utilities } \\
\text { People }\end{array}$ & 4 & 0.033 \\
\hline
\end{tabular}

Sumber: Pengolahan Data

Responden dari hasil perhitungan level sigma dapat kita lihat bahwa tingkat kualitas di Unit Usaha Wedang Uwuh "Sruput" masih jauh dari target lean six sigma.Oleh Karena itu saran yang diberikan kepada Unit Usaha Wedang Uwuh "Sruput" berupa tindakan perbaikan yang telah dianalisa dalam penelitian ini.

Berdasarkan hasil perhitungan waste diatas maka ada tiga waste yang paling berpengaruh terhadap kinerja produksi perusahaan yaitu Waiting, Defective Product, Transportation.

Sigma Level

Perhitungan level sigma dilakukan dengan rumus sebagai berikut:

Formula Excel six sigma (Evans, 2007):

$=$ NORMSINV $(1 \mathrm{dpmo} / 1000.000)+\operatorname{SHIFT}(1)$

Sebelum memasukkan angka-angka tersebut kedalam formulasi excel diatas maka dilakukan perhitungan DPMO (Defect per Milion Opportunity). Adapun rumus yang digunakan untuk mencari DPMO tersebut adalah sebagai berikut:

Rumus untuk Menghitung DPMO

(Gasperz, 2002):

$$
\frac{\text { Tingkat cacat }}{\text { Tingkat produksi } x \text { CTQ Potensial }} \times 1.000 .000
$$

Level Sigma Early Check

Perhitungan level sigma pada tahap early check akan memberikan informasi kualitas kinerja karyawan yang sebenarnya sebelum produk yang dinyatakan cacat akan diperbaiki ulang. Menghitung DPMO:

CTQ $=3$

Tingkat cacat $=9139$ unit

Tingkat Produksi $=45692$ unit

$$
\begin{aligned}
\text { Maka DPMO } & =\frac{9139}{45692 \times 3} \times 1.000 .000 \\
& =66671.04
\end{aligned}
$$

Menghitung Level Sigma:

$=$ NORMSINV $(1-\mathrm{dpmo} / 1000.000)+$ SHIFT

$=$ NORMSINV $(1-66671.04)+1,5$

Hasilnya adalah 3.001

Jadi tingkat kualitas produk pada pemeriksaan awal early check berada di level 3.001 sigma. Sehingga hasil ini menunjukkan bahwa masih sangat banyak kesalahan yang terjadi dalam proses produksi.

\section{A. Level Sigma Akhir}

Tahap seleksi akhir pada final check akan dijadikan tolak ukur kualitas produk di Unit Usaha Wedang Uwuh "Sruput",sehingga data yang digunakan meliputi hasil pemeriksaan final Check dan data produk Afkir.

Menghitung DPMO

$\mathrm{CTQ}=3$

Tingkat Cacat $=$ Cacat Final Check Repaired + cacat Afkir

$$
\begin{aligned}
& =22845+441 \\
& =23286 \text { unit }
\end{aligned}
$$

Tingkat Produksi $=45692$ Unit

$$
\begin{aligned}
\text { Maka DPMO } & =\frac{23286}{45692 \times 3} \times 1.000 .000 \\
& =169876.56
\end{aligned}
$$

Menghitung Level Sigma:

$=$ NORMSINV $(1-$ dpmo $/ 1000000)+$ SHIFT

$=$ NORMSINV(1-169876.56/1000000)+1,5

Hasilnya adalah 2.455

Jadi tingkat kualitas produk sarung tangan secara keseluruhan di Unit Usaha Wedang Uwuh Sruput berada pada level 
2.455 sigma, dimana angka ini masih jauh dari target konsep Six sigma Motorola yang berada pada level 6 sigma dengan kesalahan paling banyak 3.4 cacat per sejuta kemungkinan dan dalam waktu yang sama memberi kesempatan agar rata-rata produksi bergeser sebanyak 1.5 deviasi standar.

\section{Perhitungan Metode Taguchi}

1. Hasil identifikasi faktor-faktor yang mempengaruhi output Wedang Uwuh Sruput

Berdasarkan identifikasi dan hasil beberapa kali proses produksi,terjadinya perbedaan hasil produksi (output) Wedang Uwuh Sruput yaitu:

a.Perbedaan Kadar Gula

b.Perbedaan Kadar Jahe

c.Perbedaan jumlah air yang digunakan

d.Penggunaan bahan baku yang berbeda spesifikasi

e.Lama proses produksi yang tidak sama

f.Proses produksi yang masih manual

2. Percobaan komposisi/formula Wedang Uwuh Sruput

1)Variabel respon, yaitu: Rasa Wedang Uwuh Sruput,yang didapatkan dari hasil respon konsumen

2) Variabel bebas/faktor, terdiri dari:

a)Kadar Gula (Kg), yaitu 2,8; 2,9; 3,0

b) Kadar Jahe (Kg), yaitu 1,$0 ; 1,2 ; 1,4$

c)Kadar Air (L), yaitu 5,0; 5,1; 5,2

d)Kayu Secang (Gr), yaitu 200, 210, 220

Percobaan dilakukan sebanyak 5 kali dengan berbagai level dari faktor yang diujicobakan kepada para konsumen untuk dapat langsung mengetahui respon dari konsumen sebagai segmen pasar yang dituju.Konsumen yang disasar dalam uji coba ini berkisar antara 5-70 tahun, baik lakilaki maupun perempuan.

\section{Analyze}

Pada tahap analyze akan menganalisis hasil pengukuran menggunakan Pareto Diagram, Cause Effect Diagram, Five Why's, $5 W+1 H$ method.

A. Pareto Diagram

a. Diagram Pareto Waste Berpengaruh

$\begin{array}{ccr}\text { Hasil } & \text { pada } & \text { Diagram } \\ \text { Paretomenunjukkan } & \text { bahwa } & \text { tingkat }\end{array}$

pemborosan yang paling besar adalah waiting.

b. Analisa Waste Defective Product

Berdasarkan hasil analisa waste berpengaruhdari delapan waste menurut konsep lean,Defective product merupakan permasalahan yang dominan yang harus dicari akar penyebabnya dengan segera.

b.1. Analisa Diagram Pareto earlycheck

Pada Diagram Pareto earlycheck terlihat bahwa tingkat permasalahan utama terjadi pada rasa kurang manis yaitu mencapai angka 3655 produk atau sama dengan $40 \%$ dari seluruh total kecacatan produk yang menyebabkan ketidaksesuaian produk adalah cacat rasa kurang manis sangat mendominasi dari lima kriteria cacat pada produk Wedang Uwuh instan "Sruput".Jadi permasalahan yang paling utama untuk ditanggulangi adalah perbaikan dari rasa kurang manis.

\section{b.2. Analisa Diagram Pareto Final Check}

Dari hasil diagram pareto dapat dilihat bahwa kecacatan rasa kurang manis masih menjadi permasalahan utama yang harus segera diselesaikan dalam proses.bJika kita lihat dari pemeriksaan awal rasa kurang manis sebesar 3655 produk dan sampai kepada pemeriksaan akhir masih terdapat 9138 produk yang harus dilakukan rework karena kesalahan rasa kurang manis.

Bila keadaan ini tidak segera diatasi maka akan mempengaruhi biaya produksi yang tinggi karena perusahaan harus melakukan jam lembur (overtime) pada karyawan.

\section{b.3. Analisa Diagram Pareto Cacat Afkir}

Hasil diagram pareto dapat dilihat bahwa frekuensi penyebab cacat afkir tertinggi terjadi pada kualitas rasa kurang manis.Pengamatan dilapangan memberikan informasi bahwa salah satu yang menjadi permasalahan adalah tidak adanya kriteria baku atau tertulis yang digunakan sebagai acuan dalam melakukan seleksi tersebut.Dari hasil analisa diagram pareto yang menunjukkan bahwa kualitas rasa kurang manis adalah faktor terbesar yaitu $44.44 \%$ dari seluruh frekuensi jenis cacat afkir.Oleh karena itu permasalahan dalam 
kualitas rasa kurang manis menjadi prioritas utama yang harus dicari penyebabnya.

\section{c. Analisa Waste Transportation} Transportation merupakan permasalahan waste yang harus dicari akar penyebabnya dengan segera.Sehingga perlu dilakukan analisa terhadap masing-masing aktivitas yang menyebabkan pemborosan. Aktivitas tersebut berhubungan dengan proses produksi.

B. Cause Effect Diagram

Analisa Fishbone Diagram Cacat Rasa Kurang Manis

Berdasarkan analisa diagram pareto yang telah dilakukan sebelumnya,cacat rasa kurang manis merupakan jenis cacat yang terbesar dalam proses pembuatan produk wedang uwuh.Dari hasil perhitungan level sigma dapat kita lihat bahwa tingkat kualitas di Unit Usaha Wedang Uwuh "Sruput"masih jauh dari target lean six sigma.Oleh karena itu tindakan perbaikan yang paling utama untuk dilakukan dalam meningkatkan kualitas adalah membentuk departemen research and development, agar ada bagian khusus yang meneliti dan meningkatkan kualitas produk.

Berdasarkan hasil analisis, penyebab yang menjadi akar masalah dalam cacat rasa kurang manis terdapat pada faktor manusia,faktor material,faktor mesin dan faktor metode.Sehingga ke empat faktor tersebut akan dianalisa lebih mendalam menggunakan metode Five Why's.

\section{Metode Five Why's \\ C.1.Rasa Kurang Manis}

Metode Five Why's akan menganalisa secara mendalam mengenai faktor penyebab rasa kurang manis yang telah ditemukan dari hasil Brainstorming Fishbone Diagram.Pada cacat rasa kurang manis,metode five Why's akan digunakan untuk menganalisa faktor manusia,faktor material,faktor mesin dan faktormetode.

\footnotetext{
4.Improve

Pada tahap ini akan dilakukan penentuan rencana tindakan untuk meningkatkan kualitas produk sehingga nilai sigma mencapai 6 sigma.
}

D. Metode $5 \mathrm{~W}+1 \mathrm{H}$

Dilakukan analisis metode $5 \mathrm{~W}+1 \mathrm{H}$ untuk cacat rasa kurang manis.

\section{Control}

Dalam rangka mempertahankan peningkatan yang telah dicapai,maka perlu adanya tindakan pengecekan(control)secara rutin agar proses yang telah berjalan dengan baik tidak mengendur kembali.Oleh karena itu ada beberapa langkah yang diambil yaitu membuat rencana control dan Standard Operating Procedure(SOP).

Desain Standard Operating Procedur

Standard Operating Procedure (SOP) adalah dokumen yang berisi serangkaian instruksi tertulis yang dibakukan mengenai berbagai proses penyelenggaraan administrasi perusahaan yang berisi cara melakukan pekerjaan,waktu pelaksanaan,tempat penyelenggaraan dan yang berperan dalam kegiatan.

a. SOP Proses Mempersiapkan Bahan Baku. Prosedur Proses Mempersiapkan Bahan Baku.

Tujuan: Meningkatkan kualitas produk dengan mengurangi cacat.

Ruang Lingkup: Ruang lingkup mencakup seluruh kegiatan yang dilakukan pada proses mempersiapkan bahan baku.

Tanggung jawab: Kepala Produksi dalam aktivitas mempersiapkan bahan baku.

b. SOP Proses Pengambilan sari bahan baku. Prosedur Proses Pengambilan sari bahan baku.

Tujuan: Meningkatkan kualitas produk dengan mengurangi kesalahan dalam memasak.

Ruang Lingkup: Ruang lingkup SOP ini mencakup Bagian Proses Pengambilan sari bahan baku, bagian pembelian, bagian material dan Kepala Produksi.

Tanggung Jawab: Staff bagian Proses Pengambilan sari bahan baku bertanggung jawab pada Kepala Produksi. Bagian Pembelian bertanggung jawab kepada Manajer Produksi.

c. SOP Proses Pencampuran bahan baku.

Prosedur Proses Pencampuran bahan baku.

Tujuan: Meningkatkan kualitas produk dengan mengurangi kesalahan dalam memasak. 
Ruang Lingkup: Ruang lingkup SOP ini mencakup Bagian Proses Pencampuran bahan baku, bagian pembelian, bagian material dan Kepala Produksi.

Tanggung Jawab: Staff Proses Pencampuran bahan baku bertanggung jawab pada Kepala Produksi. Bagian Pembelian bertanggung jawab kepada Manajer Produksi.

d. SOP Proses Pengkristalan.

Prosedur Proses Pengkristalan.

Tujuan: Meningkatkan kualitas produk dengan mengurangi kesalahan dalam Proses Pengkristalan

Ruang Lingkup: Ruang lingkup SOP ini mencakup Bagian Proses Pengkristalan dan Kepala Produksi.

Tanggung Jawab: Staff Proses Proses Pengkristalan bertanggung jawab pada Kepala Produksi.

e. SOP Proses Penghalusan Granul Wedang Uwuh.

Prosedur Proses Penghalusan Granul Wedang Uwuh.

Tujuan: Meningkatkan kualitas produk dengan mengurangi kesalahan dalam Proses Penghalusan Granul Wedang Uwuh.
Ruang Lingkup: Ruang lingkup SOP ini mencakup Bagian Proses Penghalusan Granul Wedang Uwuh dan Kepala Produksi. Tanggung Jawab: Staff Proses Proses Penghalusan Granul Wedang Uwuh bertanggung jawab pada Kepala Produksi.

f. SOP Proses Pengemasan Wedang Uwuh.

Prosedur Proses Pengemasan Wedang Uwuh.

Tujuan: Meningkatkan kualitas produk dengan mengurangi kesalahan dalam Proses Pengemasan Wedang Uwuh.

Ruang Lingkup: Ruang lingkup SOP ini mencakup Bagian Proses Pengemasan Wedang Uwuh, bagian material dan Kepala Produksi.

Tanggung Jawab: Staff Proses Pengemasan Wedang Uwuh bertanggung jawab pada Kepala Produksi.

\section{Analisis Hasil Taguchi}

Berdasarkan hasil penyebaran kuesioner didapatkan bahwa hasil rata-rata preferensi konsumen pada Tabel 4 Signal to Noise Ratio (SNR) berikut:

\begin{tabular}{|c|c|c|c|c|c|c|c|c|c|c|c|}
\hline \multicolumn{10}{|c|}{ Matriks Ortogonal L27 $\left(3^{\wedge} 13\right)$} & \multirow{3}{*}{\multicolumn{2}{|c|}{ SNR }} \\
\hline \multirow{2}{*}{ Eksp } & \multicolumn{4}{|c|}{ Faktor dan Interaksi } & \multicolumn{3}{|c|}{ Replikasi } & \multirow{2}{*}{ Jumlah } & \multirow{2}{*}{ Mean } & & \\
\hline & A & $\mathrm{B}$ & $\mathrm{C}$ & D) & 1 & 2 & 3 & & & & \\
\hline 9 & $2,8 \mathrm{~kg}$ & $1,4 \mathrm{~kg}$ & $5,4 \mathrm{~L}$ & $210 \mathrm{gr}$ & 4 & 4 & 3 & 11 & 3,666667 & 13,66667 & 11,35663 \\
\hline 10 & $2,9 \mathrm{~kg}$ & $1,0 \mathrm{~kg}$ & $5,0 \mathrm{~L}$ & $2 \operatorname{logr}$ & 4 & 4 & 5 & 13 & 4,333333 & 19 & 12,78754 \\
\hline 11 & $2,9 \mathrm{~kg}$ & $1,0 \mathrm{~kg}$ & $5,2 \mathrm{~L}$ & $220 \mathrm{gr}$ & 3 & 4 & 4 & 11 & 3,666667 & 13,66667 & 11,35663 \\
\hline 12 & $2,9 \mathrm{~kg}$ & $1,0 \mathrm{~kg}$ & $5,4 \mathrm{~L}$ & $200 \mathrm{gr}$ & 4 & 3 & 3 & 10 & 3,333333 & 11,33333 & 10,54358 \\
\hline 13 & $2,9 \mathrm{~kg}$ & $1,2 \mathrm{~kg}$ & $5,0 \mathrm{~L}$ & $220 \mathrm{gr}$ & 4 & 5 & 4 & 13 & 4,333333 & 19 & 12,78754 \\
\hline 14 & $2,9 \mathrm{~kg}$ & $1,2 \mathrm{~kg}$ & $5,2 \mathrm{~L}$ & $200 \mathrm{gr}$ & 4 & 4 & 4 & 12 & 4 & 16 & 12,0412 \\
\hline 15 & $2,9 \mathrm{~kg}$ & $1,2 \mathrm{~kg}$ & $5,4 \mathrm{~L}$ & $210 \mathrm{gr}$ & 4 & 4 & 3 & 11 & 3,6666667 & 13,66667 & 11,35663 \\
\hline 16 & $2,9 \mathrm{~kg}$ & $1,4 \mathrm{~kg}$ & $5,0 \mathrm{~L}$ & $200 \mathrm{gr}$ & 4 & 5 & 5 & 14 & 4,666667 & 22 & 13,42423 \\
\hline 17 & $2,9 \mathrm{~kg}$ & $1,4 \mathrm{~kg}$ & $5,2 \mathrm{~L}$ & $210 \mathrm{gr}$ & 5 & 4 & 5 & 14 & 4,666667 & 22 & 13,42423 \\
\hline & & & Rata & & & & & & 3,962963 & & \\
\hline
\end{tabular}

Berdasarkan hasil Signal to Noise Ratio (SNR) didapatkan bahwa komposisi yang paling tepat berdasarkan preferensi konsumen yaitu Gula 2,9 kg;Jahe 1,4;Air 5 L dan Kayu Secang 200 gr.

\section{KESIMPULAN}

1. Wastewaiting memiliki bobot tertinggi yaitu 0.252 dengan ranking 31 .
2. Perhitungan nilai sigma pada early check berada pada tingkat 3.001 sigma dan final check pada tingkat 2.455 sigma.

3. Hasil perhitungan level sigma menunjukkan bahwa tingkat kualitas di Unit Usaha Wedang Uwuh Instan "Sruput" masih jauh dari target lean six sigma.Tindakan perbaikan yang paling utama dalam meningkatkan kualitas 
adalah membentuk tim researchand development.

4. Didapatkan bahwa komposisi yang paling tepat berdasarkan preferensi konsumen yaitu Gula $2,9 \mathrm{~kg}$;Jahe 1,4;Air $5 \mathrm{~L}$ dan Kayu Secang 200 gr.

\section{UCAPAN TERIMA KASIH}

Penulis mengucapkan terima kasih kepada Direktorat Riset dan Pengabdian Masyarakat Direktorat Jenderal Penguatan Riset dan Pengembangan Kementerian Riset, Teknologi dan Pendidikan Tinggi yang telah memberikan dana kegiatan penelitian.

DAFTAR PUSTAKA

[1] Vitho, I., 2013, Aplikasi Six Sigma Untuk Menganalisis Faktor-faktor
Penyebab Kecacatan Produk Crumb Rubber Sir 20 Pada PT.XYZ, Skripsi, FT, USU, Medan.

[2] Hartono, M., 2012, Meningkatkan Mutu Dengan Mengunakan Metode Taguchi, Universitas Politeknik Negeri Malang, Malang.

[3] Didik W., dan Yohan P., April 2011, Optimasi Proses Injeksi dengan Metode Taguchi, Jurnal Teknik Mesin, No. 1, Vol. 3, 24-28.

[4] Amri, 2008, Analisis Pengendalian Kualitas Produk dengan Metode Taguchi pada CV Setia Kawan, Universitas Malikussaleh.

[5] Dodi.A.P., 2013, Pengendalian Kualitas Produk Krupuk Dengan Metode Taguchi, Universitas Bina Darma Palembang, $\quad$ Palemban 